children and adolescents. In these chapters, metaphor extends out into other elements of creativity, including art, board-games and favoured cartoon characters, to help the client draw (metaphorically and literally) solutions and consider resources to their assigned concerns. This is a highlight of the text that may inspire the practitioner to utilise other methods in counselling.

Part IV (Chapters 9-10) demonstrates how elements of storytelling (StoryPlay therapy) and art therapy have been used in more recent times in response to traumatic events, including the Hurricane Iniki disaster in 1992 and September 11, 2001. It would have been ideal to see more of this area explored and discussed, especially in the area of trauma research in a post-September 11 world.

This book will be of interest to some Educational and Developmental psychologists, especially those working with children and adolescents, who are seeking alternative and creative methods, as there is no 'one size fits all' approach to counselling. It is worth visiting this text and 'allow ourselves to "enter the child within"' (p. 20) as a means to help children and adolescents.

Kathryn Kallady

Educational and Developmental Psychologist, Melbourne, Australia

\title{
Reference
}

Kopp, S. (1971). Guru: Metaphors from a psychotherapist. Palo Alto, CA: Science \& Behaviors Books.

\section{Early Childhood Theories and Contemporary Issues An Introduction}

\author{
Edited by Mine Conkbayir and Christine Pascal \\ Bloomsbury Academic, 2014, 211 pp., \$34.99 (AU paperback), ISBN: HB978-1-7809-3656-7. \\ doi:10.1017/edp.2015.4
}

This book presents a summary of a selection of theories related to early child development (0-3 years old approximately), discusses each theory and then outlines the relation of the theory to practice. It is set out in chronological order, beginning with Rousseau (1712-1778), and moves through the contribution of some well-known theorists, to consider the findings of neuroscience in the early years. The final section addresses the possibility of reconceptualising early years education in the light of the evolution of the theories, as well as how to undertake action research in such settings.

By bringing to the reader an understanding of the theories underpinning psychological practice in this field, it aims to ensure high quality, informed responses to the needs of children, their families and communities.

Each chapter follows a similar pattern, with a summary of the crucial aspects of the theory, discussion about it, practical tips on how to recognise the theory in action, and ways to test these ideas out within the child's setting. This is followed by questions for reflection, which encourage the practitioner to consider the pertinence of the theory or concept to his or her work. Case studies are included throughout, also with questions that further encourage reflective practice. Summaries at the end of each chapter give 
a synopsis of the content covered and an extensive list of references, combined with a comprehensive index, to enable further reading.

This interesting and very readable book is likely to be of most interest to those focusing their work on the very early years of childhood, who are seeking a short overview of some of the influential theories in the field and who are also interested in understanding, questioning and ensuring ongoing enhancement of their own practice.

Susan K. O'Brien

\section{The International Handbook of Research on Teachers' Belief}

Edited by Helenrose Fives and Michele Gregoire

Routledge, 2015, 502 pp., \$160.00 (AU, paperback), ISBN: 978-0415539258.

doi:10.1017/edp.2015.5

When teachers walk into classrooms, their beliefs about their role can be more critical than their lesson plan, the assessment, the students, or the structure of the class. A book dedicated to these beliefs is welcome. This book, one of the first on this topic, is more an introduction via a pleasant dip than full immersion.

The authors cite beliefs related to teaching methods (transmission, transactional, constructivist), the role and nature of dialogue, growth versus fixed, mastery versus performance, deficits, responsibility, content, learning, structures, differentiation, expectations, assessment and collective efficacy. Like most new areas, there is an (over) emphasis on commentary about how everyone needs to improve their research design but very little discussion about how to better measure or change these beliefs. Buehl and Beck introduce the limited but interesting possibilities about these relationships to practice. Most scholars claim, with limited evidence, that beliefs have an impact on student learning. Less emphasis is placed on the effects of those beliefs on willingness to stay at school, a reinvestment in learning and student beliefs, especially about learning.

A more comprehensive set of measures about beliefs is needed, while overcoming problems such as positive bias, claims versus actual beliefs and the human judgment approach (not mentioned in the book, but worth pursuing). While Australia uses the term beliefs, in the United States the word epistemology is more commonly used. In Europe, it is conceptions. How do these terms differ, and does it matter? Without more cohesion in the field, too many researchers will bypass each other because of the jingle-jangle of terms. The chapter by Lunn et al. is a great place for a beginning of such an overview. Gill and Hardin illustrate differences between beliefs and emotions, while Levin contributes an exemplary chapter of how these beliefs develop. Some areas are further researched than others. For example, compare the richness in Rubie-Davies (expectations) or Watt and Richardson (reasons for teaching) with the tentative (but optimistic) chapters on collective beliefs and in some of the chapters on content domains. This book does not explore the beliefs of principals, students, 